\title{
Reconstruction of the Head and Neck Region Using Lower Trapezius Musculocutaneous Flaps
}

\author{
Soo Kwang Yoon ${ }^{1}$, Seung Han Song ${ }^{1}$, Nakheon Kang ${ }^{1}$, Yeo-Hoon Yoon ${ }^{2}$, Bon Seok Koo ${ }^{2}$, \\ Sang-Ha Oh ${ }^{1,3}$ \\ ${ }^{1}$ Departments of Plastic and Reconstructive Surgery and ${ }^{2}$ Otorhinolaryngology-Head and Neck Surgery, ${ }^{3}$ Research Institute for Medical Science, \\ Chungnam National University College of Medicine, Daejeon, Korea
}

Background Recent literature has indicated that free flaps are currently considered the preferred choice for head and neck reconstruction. However, head and neck cancer patients are frequently treated with chemoradiotherapy, which is often associated with a poor general and local condition, and thus, such patients are ineligible for free flap reconstruction. Therefore, other reconstruction modalities should be considered.

Methods We used lower trapezius musculocutaneous (LTMC) flap based on the dorsal scapular artery to reconstruct head and neck defects that arose from head and neck cancer in 8 patients. All of the patients had undergone preoperative chemoradiotherapy.

Results There were no complications except one case of partial flap necrosis; it was treated with secondary intention. Healing in the remaining patients was uneventful without hematoma, seroma, or infection. The donor sites were closed primarily.

Conclusions The LTMC flap is the preferred flap for a simple, reliable, large flap with a wide arc of rotation and minor donor-site morbidity. The authors recommend this versatile island flap as an alternative to microvascular free tissue transfer for the reconstruction of defects in the head and neck region, for patients that have undergone preoperative chemoradiotherapy.

Keywords Head and neck neoplasms / Reconstructive surgical procedures / Chemoradiotherapy / Surgical flaps
Correspondence: Sang-Ha Oh Department of Plastic and Reconstructive Surgery, Chungnam National University Hospital, Chungnam National University College of Medicine, 282 Munhwa-ro, Jung-gu, Daejeon 301-721, Korea Tel: +82-42-280-7387 Fax: +82-42-280-7384 E-mail: djplastic@cnu.ac.kr

This study was supported by a grant from the Chungnam National University Hospital Research Fund in 2011.

No potential conflict of interest relevant to this article was reported.

Received: 30 Jun 2012 • Revised: 1 Sep 2012 • Accepted: 17 Sep 2012

pISSN: 2234-6163 • elSSN: 2234-6171 • http://dx.doi.org/10.5999/aps.2012.39.6.626• Arch Plast Surg 2012;39:626-630

\section{INTRODUCTION}

Analysis of the most recent literature shows that free flaps are currently considered the preferred choice for head and neck reconstruction. However, head and neck cancer patients are frequently treated with chemoradiotherapy, which is often associated with a poor general and local condition that may impair the healing process and reduce tolerance of surgical stress, and thus, many head and neck cancer patients are ineligible for free flap reconstruction. Regional flap surgery should be considered in this context. An ideal flap would meet the following requirements: one-step resection and reconstruction, ease and feasibility of use, short surgical duration, low complication rate, and satisfactory functional results. There are several donor sites that can be used for head and neck reconstruction including the pectoralis major musculocutaneous flap, supraclavicular artery island flap, and lower trapezius musculocutaneous (LTMC) flap [1-3]. 
The authors recommend performing head and neck reconstruction using the dorsal scapular artery, which is the deep branch of the transverse cervical artery, as a pedicle for the LTMC flap. The LTMC flap enables successful reconstruction without severe complications, demonstrating the advantages and usefulness of such surgery.

\section{METHODS}

\section{Patients}

From February 2009 to February 2012, pedicled LTMC flaps supplied by the dorsal scapular artery were used for reconstruction of head and neck defects in 8 cancer patients.

\section{Surgical technique}

A Doppler ultrasound was performed preoperatively to determine the transverse cervical artery and the dorsal scapular artery were available and usable. Flap elevation is performed first, in which the dorsal scapular artery is the main vessel. The flap can be extended far distal $(10$ to $15 \mathrm{~cm}$ ) to the inferior angle of the scapula. It is necessary to carefully examine the dorsal scapular artery with a Doppler ultrasound because the dorsal scapular artery partially overlies the scapula and could be confused with the superficial cervical artery. The operation is generally performed with the patient in the lateral decubitus position so that the arm is flexible and the scapula can be shifted while the pedicle is being dissected. The muscle margins, the medial border of the scapula, and the thoracic spine down to the twelfth vertebra are marked on the back. One-third of the skin island must be over the trapezius muscle closer to the vertebral spine to ensure musculocutaneous blood flow, and it should not be extended more than $10 \mathrm{~cm}$ distal to the inferior angle of the scapula (Fig. 1). After incision and identification of the margin of the latissimus dorsi and trapezius muscles, the muscle is elevated and the course of the dorsal scapular artery can be observed. An incision is then made along the medial border of the scapula, and the flap is elevated by cutting the muscle fibers and following straight along the pedicle vessels. Because of the size and course of the vessels at this level, magnification is helpful. The descending branch of the dorsal scapular artery running deep into the major rhomboid muscle has to be divided at the point where it appears between the rhomboid muscles. The minor rhomboid muscle can be divided to widen the arc of rotation. The arc of rotation is also limited because the vessel follows a deep course to the levator scapulae muscle, which should not be divided. If necessary, the division can be continued up to the levator scapulae muscle, achieving an average diameter of the dorsal scapular artery. Care must be taken to avoid injury to the accompanying dorsal scapular nerve. The flap can then be transferred through a subcutaneous tunnel to the recipient site, or dissection can continue under the levator scapulae muscle to the lateral neck region to widen the arc of rotation [4].

\section{Fig. 1. Preoperative design of the LTMC flap}

A Doppler ultrasound was used to trace the transverse cervical artery (TCA) and the dorsal scapular artery (DSA). The pedicle of the lower trapezius musculocutaneous (LTMC) flap is the DSA. The muscle margins, the medial border of the scapula, and the thoracic spine down to the twelfth vertebra are marked on the back (line T). Onethird of the skin island must be over the trapezius muscle and should not be extended more than $10 \mathrm{~cm}$ distal to the inferior angle of the scapula (line S).

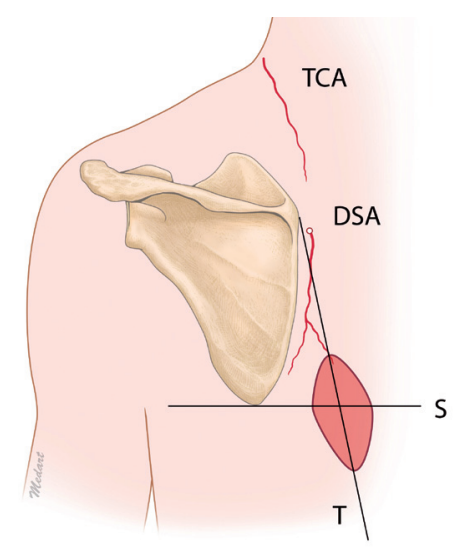

Table 1. Clinical analysis of the patients

\begin{tabular}{|c|c|c|c|c|c|c|}
\hline Patient & Age/Sex & Etiology/Location & $\begin{array}{l}\text { Defect size } \\
\left(\mathrm{cm}^{2}\right)\end{array}$ & $\begin{array}{l}\text { Flap size } \\
\left(\mathrm{cm}^{2}\right)\end{array}$ & Comorbidities & $\begin{array}{l}\text { Complication/ } \\
\text { Secondary procedure }\end{array}$ \\
\hline 1 & $66 / \mathrm{M}$ & Bone exposure d/t tonsillar cancer/Lt & $1 \times 4$ & $4 \times 6$ & DM, HTN & None \\
\hline 2 & $75 / \mathrm{M}$ & Parotid cancer/Rt & $6 \times 5$ & $7.5 \times 5$ & HTN & Partial flap necrosis/None \\
\hline 3 & $52 / F$ & Glottic cancer/Lt & $5 \times 6$ & $5 \times 7$ & & None \\
\hline 4 & $62 / F$ & Hypopharyngeal cancer/Lt & $7 \times 5$ & $8 \times 7$ & DM, HTN & None \\
\hline 5 & 49/M & Laryngeal cancer/Rt & $6 \times 5$ & $7 \times 6$ & & None \\
\hline 6 & $48 / \mathrm{M}$ & Tongue cancer/Lt & $8 \times 7$ & $8 \times 8$ & & None \\
\hline 7 & $55 / \mathrm{M}$ & Tongue cancer/Lt & $8 \times 8$ & $9 \times 8$ & DM, HTN & None \\
\hline 8 & $49 / M$ & Parotid cancer/Lt & $8 \times 6$ & $8 \times 8$ & & None \\
\hline
\end{tabular}




\section{RESULTS}

A local complication of partial flap necrosis occurred in $1 \mathrm{pa}-$ tient who was treated with a dressing. In the remaining patients, healing was uneventful without hematoma, seroma, or infections. In all of the cases, the donor site could be closed directly, and trauma to the lower part of the trapezius and the minor rhomboid muscle caused no functional problems for scapula or shoulder mobility (Table 1).

\section{Case 1}

A 66-year-old male was diagnosed with tonsillar cancer. He underwent radiotherapy 38 times with a total of 6,940 cGY and chemotherapy 5 times with cisplatin; during this period diffuse skin necrosis and necrotizing fasciitis developed. After the infection and necrotic tissue were removed, a split-thickness skin graft was applied. However, the patient had a $1 \times 4 \mathrm{~cm}$ sized bone exposure near the submandibular area. The patient required continuous chemoradiotherapy after the operation; therefore, regional flap surgery was planned. A LTMC flap with the dorsal scapular artery as a base was placed on the defect. A subcutaneous tunnel into which the vascular pedicle is usually inserted was not made; instead, an incision was made to reduce the compression arising from the external environment. The donor site was then covered with primary repair (Fig. 2).

\section{Fig. 2. Bone exposure at the left submental area}

(A) Preoperative defect in the submental region. (B) Marking of the dorsal scapular artery and flap planning on the back. (C) Elevated flap as an island flap. (D) Postoperative 3 months.
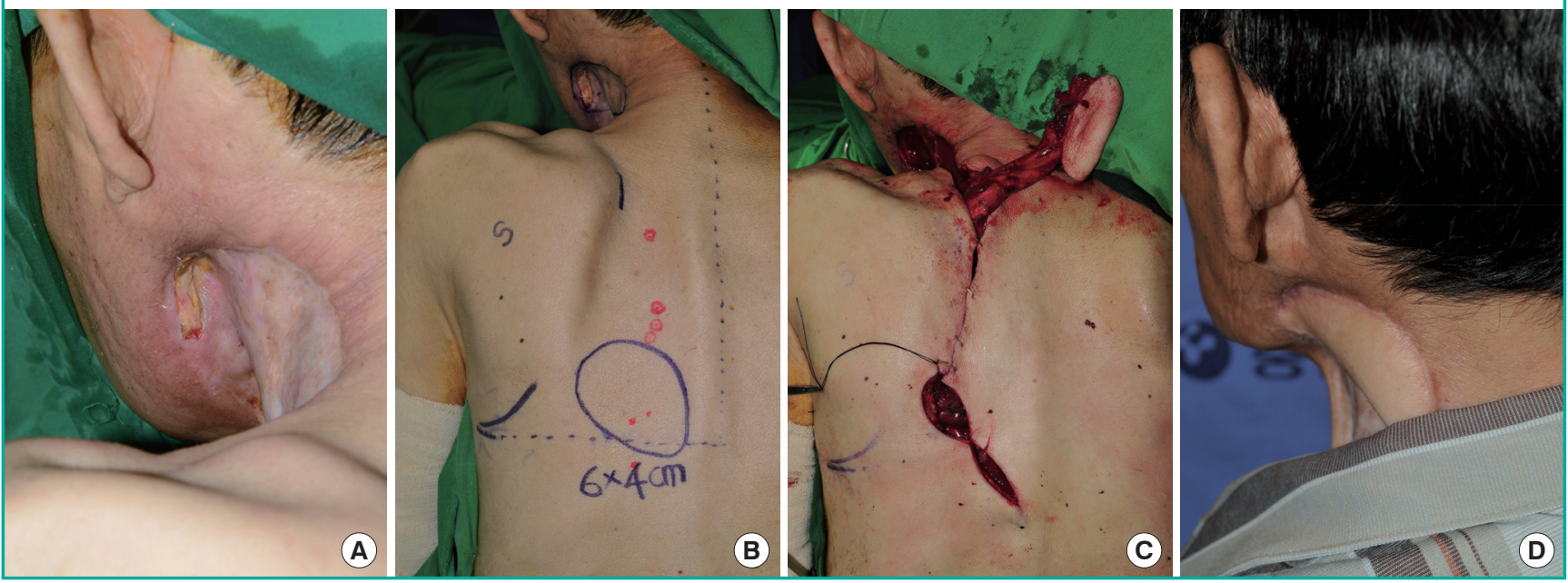

Fig. 3. Defect on the right lateral side of neck after tumor ablation

(A) Preoperative defect in the lateral side of the neck region. (B) Elevated flap as an island flap. (C) Partial flap necrosis occurred in the distal part of the flap. (D) Completely healed state with secondary intention for 2 months.
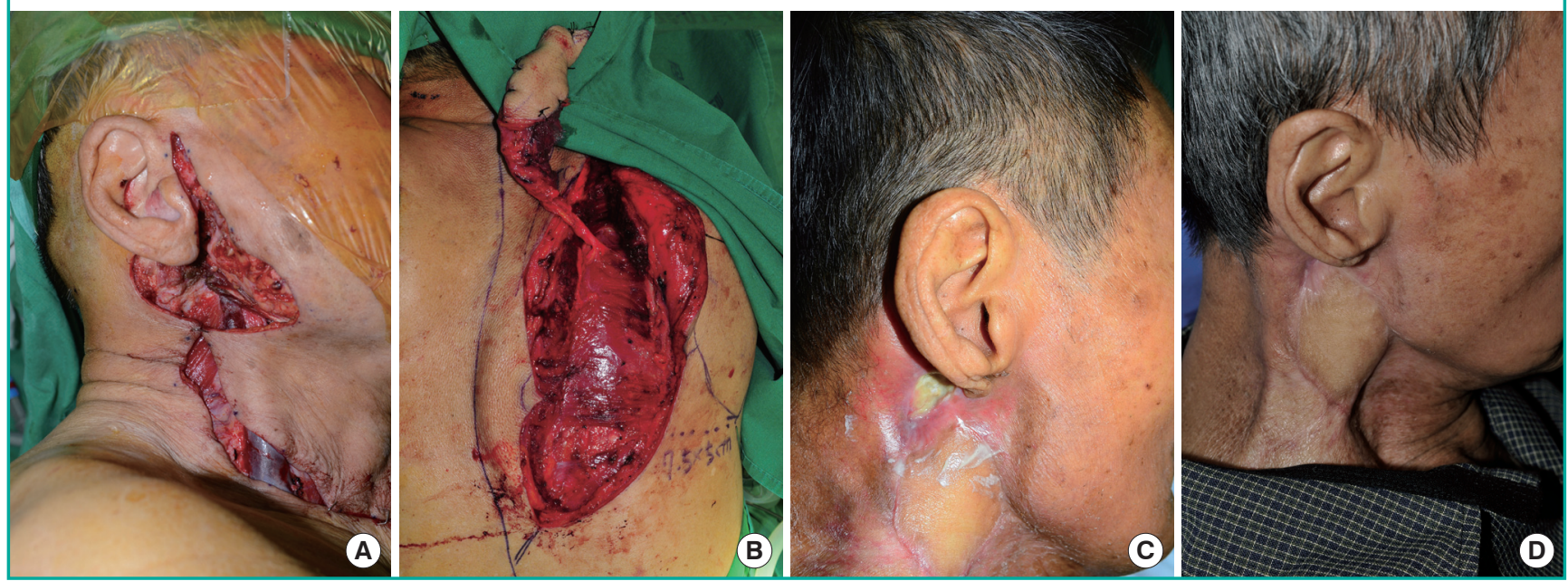


\section{Case 2}

A 75-year-old male patient was diagnosed with a parotid tumor based on a tissue diagnosis of a lump found below his right ear by the otorhinolaryngology department. He underwent preoperative radiotherapy with total of 6,300 cGy. However, the tumor size did not decrease, and surgical resection was needed. After resection, a $6 \times 5 \mathrm{~cm}$ defect remained, and a LTMC flap with the dorsal scapular artery as a pedicle was elevated and placed in the defect. There were no problems except one case of partial skin necrosis of the flap. It was healed by secondary intention within 2 months (Fig. 3).

\section{DISCUSSION}

The trapezius muscle is superficial, flat, triangular, and approximately $34 \times 18 \mathrm{~cm}$ in size; it covers the posterior cervical and interscapular thoracic areas. Along with the pectoralis and rotator cuff muscles, the trapezius suspends the pectoral girdle from its muscular origin located along the external occipital protuberance, the medial third of the superior nuchal line, the ligament nuchae, and the spinous processes of the seventh cervical and twelfth thoracic vertebrae [4]. According to the classification of Mathes and Nahai [5], the trapezius muscle has a type II vascular pattern with dominant and additional minor vascular pedicles. The transverse cervical artery with its branches is the major feeding artery. The additional minor vascular pedicles are the occipital artery and posterior intercostal artery.

Functionally and aesthetically, the muscle may be considered to have an upper and a lower portion. The upper portion of the muscle inserts along the lateral third of the clavicle. It receives the majority of its blood supply from the transverse cervical artery. It also contains the spinal accessory nerve, which courses along its deep surface and provides motor innervations to the entire muscle. The lower portion of the muscle inserts along the lateral spine of the scapula; it is a dispensable subunit. The superficial and deep branches of the transverse cervical artery supply blood to this portion of the muscle [6-11]. The distinction between the upper and lower parts of the trapezius allows the lower portion of the muscle to be used for wound coverage while preserving normal shoulder function [12].

The authors generally used a LTMC flap with the dorsal scapular artery, the deep branch of the transverse cervical artery, as a pedicle for reconstruction. This flap can be elongated to about 10 to $15 \mathrm{~cm}$ (measured from the tip of the scapula) with minimal damage to the nerve and with preservation of the muscle fibers from the proximal trapezius muscle. Moreover, if the pedicle is damaged during surgery, it can be replaced with the superficial cervical artery $[13,14]$. For a middle trapezius musculocutaneous (MTMC) flap, the superficial cervical artery (the superficial branch of the transverse cervical artery) is used as the vascular pedicle. However, the accessory spinal nerve is located parallel to the vascular pedicle, and there is thus a higher risk of nerve damage during detachment. The LTMC flap is thin and pliable, and also has a very long constant pedicle and minor donor-site morbidity.

Reconstruction of a head and neck defect with a local flap in combination with planned radiation therapy may delay wound healing, and a free flap might cause severe morbidity in patients with a poor general condition or those with a tumor with a poor prognosis $[1,15]$. Thus, if a one-step reconstruction is planned for such patients, regional flap surgery is preferable. Other regional flaps include the pectoralis major musculocutaneous flap and the supraclavicular artery island flap. The pectoralis major musculocutaneous flap provides thick muscle volume so it can protect the important neck organs, but it also creates an abnormal bulge at the root of the neck that causes neck stiffness. When we elevated the pectoralis major musculocutaneous flap, the dissection area was radiated, which compromised the wound healing $[2,16]$. The supraclavicular artery island flap is near the recipient site; thus, flap color and texture are very similar to that of the recipient site. However, because it has a short pedicle, it can cover only the lower border of the face and neck $[3,17]$.

The LTMC and MTMC flaps are distant from the defect area and can be reliablebecause both have abundant blood flow, minor donor-site morbidity, and have a very long constant pedicle whereas the supraclavicular artery island has a short pedicle. These flaps are also thin and pliable whereas the pectoralis major musculocutaneous flap is thick. To sum up, lower and MTMC flaps have a wide arc of rotation, low donor-site morbidity, are richly vascularized, and ensure serviceable skin coverage of areas as far cephalic as the vertex of the skull without evidence of tension or traction. Our clinical studies clearly show that these flaps are particularly useful in patients who have experienced previous radiation injury, or who are ineligible for free flap surgery for head and neck reconstruction.

\section{REFERENCES}

1. Choi $\mathrm{EC}$, Kim $\mathrm{CH}, \mathrm{Kim} \mathrm{SH}$, et al. The role of pectoralis major myocutaneous flap in the era of free flap. Korean J Head Neck Oncol 2001;17:190-3.

2. Ariyan $S$. The pectoralis major myocutaneous flap. A versatile flap for reconstruction in the head and neck. Plast Reconstr Surg 1979;63:73-81.

3. Pallua N, Magnus Noah E. The tunneled supraclavicular is- 
land flap: an optimized technique for head and neck reconstruction. Plast Reconstr Surg 2000; 105:842-51.

4. Netterville JL, Wood DE. The lower trapezius flap. Vascular anatomy and surgical technique. Arch Otolaryngol Head Neck Surg 1991;117:73-6.

5. Mathes SJ, Nahai F. Classification of the vascular anatomy of muscles: experimental and clinical correlation. Plast Reconstr Surg 1981;67:177-87.

6. Mathes SJ, Nahai F. Clinical atlas of muscle and musculocutaneous flap. St. Louis: Mosby; 1979.

7. McCraw JB, Dibbell DG. Experimental definition of independent myocutaneous vascular territories. Plast Reconstr Surg 1977;60:212-20.

8. McCraw JB, Dibbell DG, Carraway JH. Clinical definition of independent myocutaneous vascular territories. Plast Reconstr Surg 1977;60:341-52.

9. Urken ML, Naidu RK, Lawson W, et al. The lower trapezius island musculocutaneous flap revisited. Report of 45 cases and a unifying concept of the vascular supply. Arch Otolaryngol Head Neck Surg 1991;117:502-11.

10. Baek SM, Biller HF, Krespi YP, et al. The lower trapezius island myocutaneous flap. Ann Plast Surg 1980;5:108-14.

11. Haas F, Weiglein A, Schwarzl F, et al. The lower trapezius musculocutaneous flap from pedicled to free flap: anatomi- cal basis and clinical applications based on the dorsal scapular artery. Plast Reconstr Surg 2004;113:1580-90.

12. Lynch JR, Hansen JE, Chaffoo R, et al. The lower trapezius musculocutaneous flap revisited: versatile coverage for complicated wounds to the posterior cervical and occipital regions based on the deep branch of the transverse cervical artery. Plast Reconstr Surg 2002;109:444-50.

13. Angrigiani C, Grilli D, Karanas YL, et al. The dorsal scapular island flap: an alternative for head, neck, and chest reconstruction. Plast Reconstr Surg 2003;111:67-78.

14. Tan KC, Tan BK. Extended lower trapezius island myocutaneous flap: a fasciomyocutaneous flap based on the dorsal scapular artery. Plast Reconstr Surg 2000; 105:1758-63.

15. Ugurlu K, Ozcelik D, Huthut I, et al. Extended vertical trapezius myocutaneous flap in head and neck reconstruction as a salvage procedure. Plast Reconstr Surg 2004;114:339-50.

16. Ariyan S. Further experiences with the pectoralis major myocutaneous flap for the immediate repair of defects from excisions of head and neck cancers. Plast Reconstr Surg 1979;64:605-12.

17. Chiu ES, Liu PH, Friedlander PL. Supraclavicular artery island flap for head and neck oncologic reconstruction: indications, complications, and outcomes. Plast Reconstr Surg 2009; 124:115-23. 